\title{
The Energetics of Ion-Pair and Hydrogen-Bonding Interactions in a Helical Peptide $^{\dagger}$
}

\author{
J. Martin Scholtz,,,$+ \$$ Hong Qian, $\|, \perp$ Virginia H. Robbins, ${ }^{\ddagger}$ and Robert L. Baldwin ${ }^{\ddagger}$ \\ Department of Biochemistry, Stanford University School of Medicine, Stanford, California 94305-5307, and \\ Institute of Molecular Biology, University of Oregon, Eugene, Oregon 97403-1229
}

Received May 18, 1993; Revised Manuscript Received June 30, $1993^{\circ}$

\begin{abstract}
A single pair of Glu and Lys residues has been placed at four different spacings, and in both orientations, in an otherwise neutral alanine-glutamine peptide helix, and the contribution to helix stability of the different Glu-Lys interactions has been measured. The contribution from the interaction of each charged side chain with the helix macrodipole has also been determined. A side-chain interaction between Gln and Glu, when the spacing is $(i, i+4)$, has been detected and quantified. The interactions have been divided into contributions from hydrogen bonds (independent of the concentration of $\mathrm{NaCl}$ ) and from electrostatic interactions (present in $10 \mathrm{mM} \mathrm{NaCl}$, absent in $2.5 \mathrm{M} \mathrm{NaCl}$ ). The major results are as follows: (1) The $(i, i+3)$ and $(i, i+4) \mathrm{Glu}$-Lys interactions are helix-stabilizing and are similar in strength to each other, regardless of the orientation of the side chains. (2) Hydrogen bonds provide the major contribution to these side-chain interactions, as shown by the following facts. First, the major part of the interaction observed in $10 \mathrm{mM} \mathrm{NaCl}, \mathrm{pH} 7$, is still present in $2.5 \mathrm{M} \mathrm{NaCl}$. Second, the interaction found at $\mathrm{pH} 2$ is equally as strong as that found in $2.5 \mathrm{M} \mathrm{NaCl}$ at pH 7. (3) The $(i, i+4) \mathrm{Gln}-\mathrm{Glu}$ side-chain hydrogen bond is as strong as the hydrogen-bond component of the Glu-Lys interaction at both $\mathrm{pH} 2$ and $\mathrm{pH} 7$. The Gln-Glu interaction differs from the Glu-Lys interaction in being specific both for the orientation and the spacing of the residues. (4) No significant hydrogen-bonding interaction was found for the $(i, i+1)$ or $(i$, $i+2) \mathrm{Glu}-\mathrm{Lys}$ spacings, either at $\mathrm{pH} 2$ or at $\mathrm{pH} 7$, in $2.5 \mathrm{M} \mathrm{NaCl}$. At $10 \mathrm{mM} \mathrm{NaCl}$ and $\mathrm{pH} 7$, these spacings show a helix-destabilizing electrostatic interaction which probably results from stabilization of the coil conformation.
\end{abstract}

A complete understanding of the factors that contribute to $\alpha$-helix formation by short peptides in water requires a knowledge of intrinsic helix-forming tendencies of the separate amino acid residues as well as an accounting of the energetics of interactions between specific side chains. There has been much progress in determining the helix propensities of residues in a variety of experimental systems (Chakrabartty et al., 1991; Lyu et al., 1990; Merutka et al., 1990; O'Neil \& DeGrado, 1990; Padmanabhan et al., 1990), and a recent summary has appeared (Chakrabartty \& Baldwin, 1993). The role of specific side-chain interactions in stabilizing the helical structure of a peptide has been appreciated for some time [for review, see Scholtz and Baldwin (1992)]; however, a detailed quantitation of these interactions has not been investigated to the extent necessary for a complete understanding of the problem (Armstrong \& Baldwin, 1993; Gans et al., 1991; Huyghues-Despointes et al., 1993a). Here we report a detailed analysis of the electrostatic interactions present in peptides with isolated Glu and Lys residues and are able to evaluate the energetics of the interaction between side

${ }^{\dagger}$ This work was supported by grants from the National Institutes of Health: GM 31475 (to R. L. B.) and GM 20195 (to John A. Schellman). J. M. S. is a Bank of America-Giannini Foundation Post-Doctoral Fellow.

* To whom correspondence should be addressed.

‡ Stanford University School of Medicine.

8 Present address: Department of Medical Biochemistry \& Genetics, 440 Reynolds Medical Building, Texas A \& M University, College Station, TX 77843-1114.

"University of Oregon.

$\perp$ Present address: Beckman Institute, California Institute of Technology, Pasadena, CA 91125.

Abstract published in Advance ACS Abstracts, September 1, 1993. chains and the interaction of a charged side chain with the helix macrodipole.

There are two electrostatic interactions that must be considered to determine the role of charged side chains in $\alpha$-helix formation: the interaction between each of the charged side chains and the helix macrodipole and the interaction between the side chains themselves. We have elected to evaluate each electrostatic component separately by isolating a charged residue, or a pair of charged residues, in an otherwise neutral helical host peptide. We use the term ion pair to describe a simple nonbonded interaction between a pair of oppositely charged residues; the term salt bridge refers to a hydrogen-bonded ion pair (Marqusee \& Baldwin, 1987). Our data indicate that both interactions may be present in some of the peptides; however, we will use the more general term ion pair to describe the interactions observed between the charged forms of Glu and Lys. The helix macrodipole refers to the electrical property of the $\alpha$-helix backbone that arises from the partial alignment of the individual peptide dipole moments (Hol et al,, 1978). This alignment produces a substantial helix macrodipole with the four unbonded N-terminal NH and C-terminal $\mathrm{CO}$ groups contributing to the charge separation as well (Åquist et al., 1991). ${ }^{1}$ Regardless of the atomic details of the helix macrodipole, it has been shown that the net effect can be modeled by placing charges of $+0.5 q$ close to the $\mathrm{N}$-terminus and $-0.5 q$ close to the C-terminus of the helical peptide (Hol et al., 1978; Sheridan et al., 1982; Wada, 1976). Here; we refer to the charge-helix

\footnotetext{
1 In a peptide helix whose $\mathrm{N}$-terminal $\mathrm{NH}_{2}$ and $\mathrm{C}$-terminal $\mathrm{COOH}$ groups are blocked with acetyl and carboxamide, respectively, the blocking groups may hydrogen bond to free main-chain $\mathrm{NH}$ and $\mathrm{CO}$ groups, and thus reduce the number of unsatisfied $\mathrm{NH}$ and $\mathrm{CO}$ groups to 3 .
} 
dipole effect as the simple electrostatic interaction between a charged side chain and the helix macrodipole.

Our experimental goal is to determine all the factors which are involved in helix formation for peptides with charged residues and to compare the role of electrostatic interactions in helix stability to that found in protein stability. We have isolated the intrinsic helix-forming tendencies of charged residues from the two electrostatic effects in order to gain a more complete description of helix formation. The use of simple $\alpha$-helical peptides enables us to isolate and study, in detail, the role of electrostatic interactions in protein and peptide stability. The approach is general and will aid us in determining the energetics of all interactions that contribute to helix formation in peptides.

\section{EXPERIMENTAL PROCEDURES}

Experimental Measurements. Peptides were synthesized by the solid-phase method using an active ester coupling procedure, employing pentafluorophenyl esters of (9-fluorenylmethoxycarbonyl)amino acids (Atherton \& Sheppard, 1985). Peptides were cleaved from the resin and deprotected by using a $\mathrm{N}_{2}$-sparged mixture of $2 \%$ anisole, $3 \%$ ethanedithiol, $5 \%$ thioanisole, and $90 \%$ trifluoroacetic acid. Peptides were purified as described by Chakrabartty et al. (1991). Peptide purity was assessed by fast-performance liquid chromatography (Pharmacia) and by capillary electrophoresis (Applied Biosystems); purity was greater than $97 \%$ for each peptide. The primary-ion molecular weight of each peptide was confirmed by fast atom bombardment mass spectrometry.

Circular dichroism $(C D)^{2}$ measurements were made on an AVIV 60 DS spectropolarimeter equipped with a HewlettPackard Model 89100 A temperature controller. The ellipticity is reported as mean residue ellipticity, $[\theta]$, and was calibrated with (+)-10-camphorsulfonic acid. Cuvettes with $1-\mathrm{cm}$ or 1 -mm path lengths were used. The degree of helical structure in each peptide was determined by monitoring the ellipticity at $222 \mathrm{~nm}$ at $0^{\circ} \mathrm{C}$.

Concentrations of the peptide stock solutions were determined by measuring Tyr absorbance in $6 \mathrm{M}$ guanidine hydrochloride with $20 \mathrm{mM}$ phosphate buffer $\left(\epsilon_{275}=1450 \mathrm{M}^{-1}\right.$ $\mathrm{cm}^{-1}$, Brandts \& Kaplan 1973). The peptides were synthesized prior to the report by Chakrabartty et al. (1993) regarding the effect of aromatic residues on the CD signal. Since we are comparing peptides which contain a single Tyr residue at the $\mathrm{C}$-terminus, the aromatic contribution to the $\mathrm{CD}$ will not affect the results. Samples were prepared for $C D$ analysis by diluting the stock solution with a buffer consisting of $1 \mathrm{mM}$ sodium citrate, $1 \mathrm{mM}$ sodium borate, and $1 \mathrm{mM}$ sodium phosphate (CD buffer). Samples for spectral analysis were prepared in $10 \mathrm{mM}$ potassium fluoride and $1 \mathrm{mM}$ potassium phosphate. The effect of $\mathrm{pH}$ on the observed helicity at $0^{\circ} \mathrm{C}$ was investigated by lowering the $\mathrm{pH}$ of the peptide sample with aliquots of concentrated $\mathrm{HCl}$; the $\mathrm{pH}$ was measured on an Orion $\mathrm{pH}$ meter Model 601A using a Metrohm electrode and calibrated at $0^{\circ} \mathrm{C}$ by adjusting the standard solutions to the manufacturer's specifications.

Data Analysis. The measured ellipticities of each of the peptides $\left([\theta]_{\mathrm{obs}}\right)$ at $222 \mathrm{~nm}$ were converted to fractional

\footnotetext{
2 Abbreviations: ( $w_{\text {host }}$ ), average $w$-value for Ala-Gln host; $w\left(\mathrm{E}^{0}\right)$, intrinsic $w$-value for $\mathrm{Glu}^{0} ; w\left(\mathrm{E}^{-}\right)$, intrinsic $w$-value for $\mathrm{Glu}^{-} ; w_{\text {app }}\left(\mathrm{E}_{i}^{-}\right)$, apparent $w$-value for Glu at position $i$ in the host peptide; $w_{\text {app }}\left(\mathrm{K}_{j}^{+}\right)$, apparent $w$-value for $\mathrm{Lys}^{+}$at position $j$ in the host peptide; $\mathrm{CD}$, circular dichroism spectroscopy. The abbreviations for amino acids and blocking groups are A, Ala; Q, Gln; E, Glu; K, Lys; Y, Tyr; Ac, acetyl; and $\mathrm{NH}_{2}$ carboxamide.
}

helicities using the relationship $f_{\mathrm{H}}=\left([\theta]_{\text {obs }}-[\theta]_{\mathrm{c}}\right) /\left([\theta]_{\mathrm{H}}-\right.$ $\left.[\theta]_{\mathrm{C}}\right)$, where $[\theta]_{\mathrm{H}}=-40000(1-2.5 / 16)$ and $[\theta]_{\mathrm{C}}=640 \mathrm{deg}$ $\mathrm{cm}^{2} \mathrm{dmol}^{-1}$ as described by Scholtz et al. (1991b) for these 16-residue peptides at $0^{\circ} \mathrm{C}$.

The Lifson-Roig model for the helix-coil transition (Lifson \& Roig, 1961) serves as the starting point for analysis of the data. The basic theory has been modified in several ways to incorporate interactions between specific side chains and between charged side chains and the helix macrodipole. In all cases, the AQ host peptide is treated as a homopolymer, enabling a calculation of an average value for the intrinsic helix-forming tendency for the host, $\left\langle w_{\text {host }}\right\rangle$, and the nucleation parameter, $v^{2}$. These values, which employ the Lifson-Roig nomenclature of $w$ and $v^{2}$, can be converted to the more familiar Zimm-Bragg (Zimm \& Bragg, 1959) values of $s$ and $\sigma$ as described by Qian and Schellman (1992).

The standard one-sequence approximation of the LifsonRoig theory is used to calculate the intrinsic helix-forming tendency of uncharged Glu $\left(w\left(\mathrm{E}^{0}\right)\right)$ as described previously (Chakrabartty et al., 1991; Qian \& Schellman, 1992). This same treatment can also be utilized to determine the apparent, position-dependent $w$-value for a charged residue, $w_{\text {app }}\left(\mathrm{E}_{i}^{-}\right)$ and $w_{\text {app }}\left(\mathrm{K}_{j}^{+}\right)$. These latter values include contributions from the intrinsic helix-forming tendency of the guest residue as well as a position-dependent component from the chargedipole interaction of the side chain with the helix macrodipole.

Specific side-chain interactions cannot be quantified using the simple models for the helix-coil theory (Lifson \& Roig, 1961; Zimm \& Bragg, 1959). Two approaches to model specific interactions between side chains have been employed. The first model describes the interaction between a charged side chain and the helix macrodipole using a simple electrostatic treatment of the helix macrodipole in which charges of $+0.5 q$ and $-0.5 q$ are placed near the $\mathrm{N}$ - and the C-terminus, respectively, of each of the helical stretches that contribute to the overall partition function. Using a recursive method, the contributions of the simple Coulombic interaction between the side chain with a charge of $-1.0 q$ and the charges on the helix macrodipole are summed over all conformations that contribute to the partition function. The details of the method are outlined in the Appendix.

The energetics of interactions between specific side chains has been modeled by an additional modification of the basic Lifson-Roig theory for the helix-coil transition. In this modification, two guest residues with their apparent $w$-values $\left(w_{\text {app }}\left(\mathrm{E}_{i}^{-}\right)\right.$and $\left.w_{\text {app }}\left(\mathrm{K}_{j}^{+}\right)\right)$are placed at specific positions in the homopolymer host peptide. The partition function is calculated using the "nesting" approach outlined by Robert (1990). If there is no interaction between the side chains, these parameters are sufficient to calculate the observed helicity of the peptide. When there is a substantial interaction between the side chains of the guest residues, an additional free energy is needed to account for the observed helicity; that is, the apparent helix-forming tendencies alone, including any contributions from charge-dipole interactions, are not sufficient to provide the observed helicity. A statistical weight, $p$, is then included in the partition function for those conformations that involve interactions between the side chains of interest. The free energy of the side-chain interaction is given by $\Delta G^{\circ}$ $=-R T \ln p$. Additional details can be found in the Appendix.

\section{RESULTS}

Experimental Design. In order to investigate the effects of side-chain electrostatic interactions on the observed helicity of a synthetic peptide, it is imperative to have a host peptide 


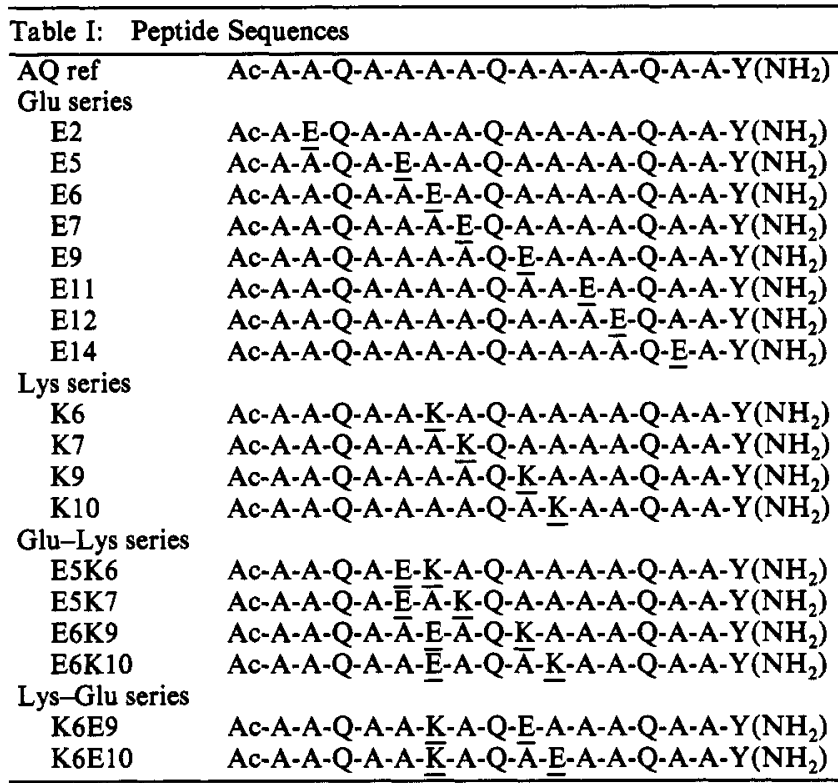

that is composed of neutral residues. The AQ host peptide used here is an ideal vehicle for these studies since we are able to place isolated charged residues at defined positions in the sequence of the otherwise neutral peptide host. The design and characterization of the AQ host peptide has been described (Scholtz et al., 1991c). The sequences and abbreviations for all of the peptides used in this study are shown in Table I. In the Glu series, the intrinsic helix-forming tendencies of $\mathrm{Glu}^{0}$ and $\mathrm{Glu}^{-}$are determined from the position dependence of the helix-destabilizing effect of a substituted Glu residue in a helical host peptide, as described by Chakrabartty et al. (1991) for glycine. The Lys series provides control peptides for determining the energetics of the side-chain interactions between Glu and Lys in the Glu-Lys and Lys-Glu series of peptides.

All the peptides used in this study show the characteristics exhibited by all alanine-based $\alpha$-helical peptides studied thus far (Scholtz \& Baldwin, 1992), namely, a CD spectrum expected for an $\alpha$-helix with minima at 222 and $208 \mathrm{~nm}$ and a maximum at $\approx 192 \mathrm{~nm}$ (data not shown). Also, the amount of helical structure decreases with increasing temperature (Scholtz et al., 1991a) with an isodichroic point at $\approx 203 \mathrm{~nm}$. These CD characteristics are not dependent on peptide concentration, suggesting that helix formation is monomeric (Padmanabhan et al., 1990). Furthermore, the helix to coil transition of all of these peptides is reversible, regardless of the method used to shift the equilibrium between the two populations.

Our primary objective is to investigate the electrostatic interaction between an isolated pair of Glu and Lys side chains. The guest residues have been placed in the center of a neutral host peptide to minimize the effects of the charged side chain with the helix macrodipole. Since the interactions of interest are electrostatic, the effects of changing the solvent conditions by adding $\mathrm{NaCl}$ and by changing the $\mathrm{pH}$ have been investigated. The fractional helicities of all of the peptides at low (pH 2.5) and neutral $\mathrm{pH}(\mathrm{pH} 7.0)$ at three different concentrations of $\mathrm{NaCl}(0.01,1.0$, and $2.5 \mathrm{M})$ are shown in Table II.

Glu Series. The effect of substituting a single Glu residue at various positions in the $A Q$ host peptide on the overall helicity at $10 \mathrm{mM} \mathrm{NaCl}$ can be seen in Figure 1. Each point is calculated from the observed helicity for a peptide with a single Glu residue substituted at the indicated position in the

\begin{tabular}{|c|c|c|c|c|c|c|}
\hline \multirow[b]{2}{*}{ peptide } & \multicolumn{3}{|c|}{$[\mathrm{NaCl}](\mathrm{M}), \mathrm{pH} 2.5$} & \multicolumn{3}{|c|}{$[\mathrm{NaCl}](\mathrm{M}), \mathrm{pH} 7.0$} \\
\hline & 0.01 & 1.0 & 2.5 & 0.01 & 1.0 & 2.5 \\
\hline $\mathbf{A Q}$ & 0.49 & 0.52 & 0.48 & 0.49 & 0.52 & 0.48 \\
\hline E2 & 0.39 & 0.43 & 0.39 & 0.49 & 0.47 & 0.41 \\
\hline E5 & 0.37 & 0.42 & 0.39 & 0.36 & 0.37 & 0.34 \\
\hline E6 & 0.38 & 0.41 & 0.38 & 0.37 & 0.38 & 0.34 \\
\hline E7 & 0.44 & 0.50 & 0.46 & 0.45 & 0.48 & 0.43 \\
\hline E9 & 0.35 & 0.35 & 0.36 & 0.29 & 0.35 & 0.29 \\
\hline E11 & 0.37 & 0.42 & 0.39 & 0.28 & 0.35 & 0.32 \\
\hline E12 & 0.43 & 0.48 & 0.44 & 0.33 & 0.41 & 0.38 \\
\hline E14 & 0.41 & 0.46 & 0.43 & 0.32 & 0.41 & 0.39 \\
\hline K6 & 0.34 & 0.39 & 0.38 & 0.34 & 0.39 & 0.38 \\
\hline K7 & 0.35 & 0.40 & 0.39 & 0.35 & 0.40 & 0.39 \\
\hline K9 & 0.37 & 0.42 & 0.40 & 0.37 & 0.42 & 0.40 \\
\hline K10 & 0.39 & 0.44 & 0.42 & 0.39 & 0.44 & 0.42 \\
\hline E5K6 & 0.26 & 0.31 & 0.31 & 0.22 & 0.28 & 0.27 \\
\hline E5K 7 & 0.28 & 0.33 & 0.32 & 0.23 & 0.29 & 0.29 \\
\hline E6K9 & 0.33 & 0.38 & 0.39 & 0.35 & 0.36 & 0.34 \\
\hline E6K10 & 0.37 & 0.43 & 0.41 & 0.39 & 0.40 & 0.37 \\
\hline K6E9 & 0.31 & 0.37 & 0.36 & 0.28 & 0.32 & 0.27 \\
\hline K6E10 & 0.30 & 0.34 & 0.35 & 0.32 & 0.33 & 0.27 \\
\hline
\end{tabular}

a Fractional helicities were determined from the observed ellipticities $\left([\theta]_{222}\right)$ at $0^{\circ} \mathrm{C}$ as described in Experimental Procedures using $[\theta]_{\mathrm{H}}=$

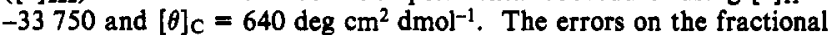
helicities are approximately \pm 0.01 .

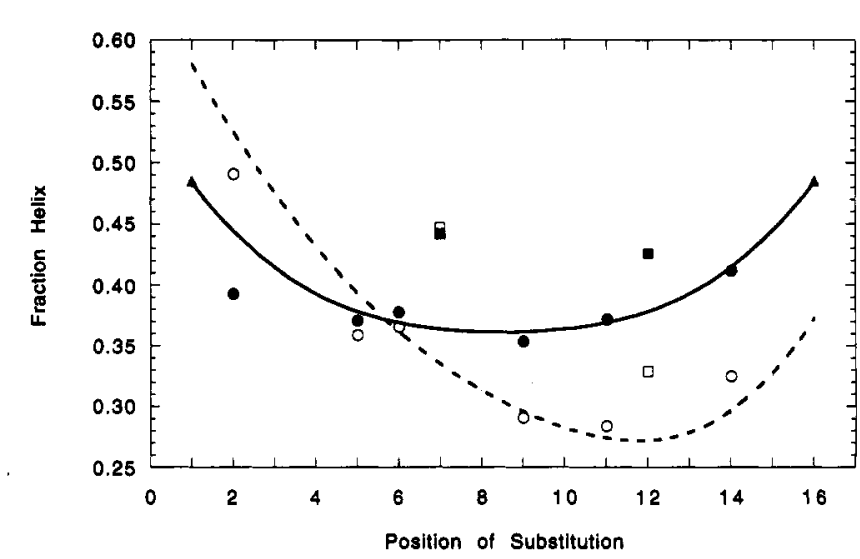

FIGURE 1: Dependence of fractional helicity on the position of a substituted Glu residue at low pH (solid symbols, Glu ${ }^{\circ}$ ) and $\mathrm{pH} 7$ (open symbols, $\mathrm{Glu}^{-}$) at $10 \mathrm{mM} \mathrm{NaCl}, 0^{\circ} \mathrm{C}$. The lines represent the best fit of the data to the standard Lifson-Roig model (pH 2.5 for $\mathrm{Glu}^{0}$, solid line and solid circles) and the charge-dipole modification of the Lifson-Roig model ( $\mathrm{pH} 7$ for $\mathrm{Glu}^{-}$, dashed line and open circles). The squares, representing the data for peptides E7 and E12, were not used in the fit because of a possible Gln-Glu interaction (see text). The triangles represent the fractional helicity of the AQ host peptide.

chain. The filled symbols are the fractional helicities at low $\mathrm{pH}\left(\mathrm{Glu}^{0}\right)$, whereas the open symbols are the results at neutral $\mathrm{pH}\left(\mathrm{Glu}^{-}\right)$. For the $\mathrm{Glu}^{0}$ data, where the entire peptide is uncharged, it is possible to calculate an intrinsic helix-forming tendency for $\mathrm{Glu}^{0}$ using the simple homopolymer approximation for the host peptide with the Lifson-Roig theory. The solid line in Figure 1 is the result of this fit, giving ( $\left.w_{\text {host }}\right)=$ 1.43 and $w\left(\mathrm{E}^{0}\right)=0.66$, using a constant value for $v^{2}=0.0038$ as determined previously (Rohl et al., 1992; Scholtz et al., $1991 \mathrm{~b})$. The triangles are the fractional helicity of the AQ host peptide. The two peptides represented by squares in Figure 1, E7 and E12, were not included in the determination of the $w$-values since there appears to be a stabilizing $(i, i+4)$ interaction between Gln and Glu in these peptides (see below).

In the $\mathrm{pH}$ range where the Glu residue is ionized, it is apparent that a substantial charge-helix dipole interaction develops. The peptides with the $\mathrm{Glu}^{-}$residue substituted near the C-terminus, which has excess negative charge from the 


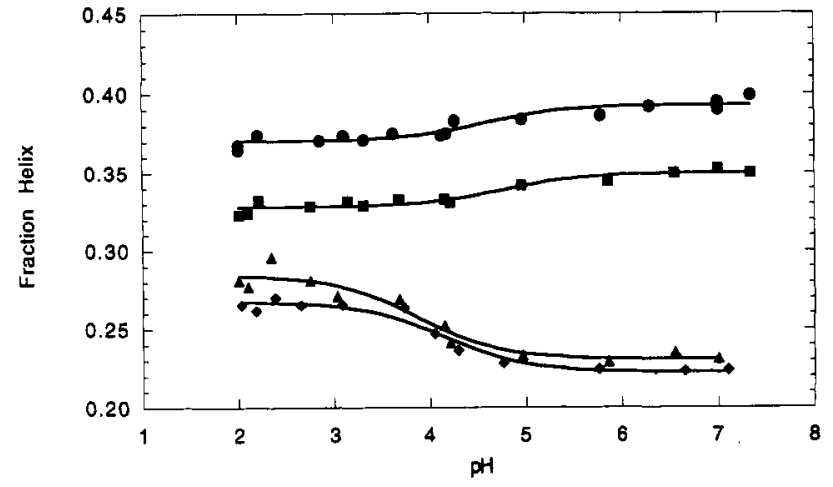

FIGURE 2: Effect of $\mathrm{pH}$ on the observed helicity of the Glu-Lys

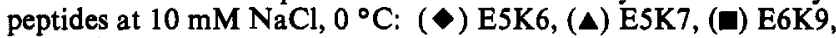
and (-) E6K10. The lines are drawn by inspection only.

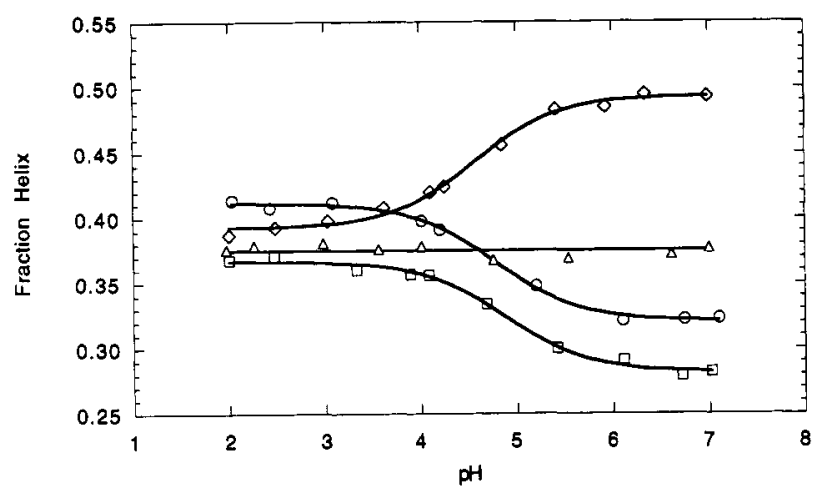

FIGURE 3: Effect of $\mathrm{pH}$ on the observed helicity of the Glu peptides at $10 \mathrm{mM} \mathrm{NaCl}, 0^{\circ} \mathrm{C}:(\diamond) \mathrm{E} 2,(\Delta) \mathrm{E} 6,(\square) \mathrm{E} 11$, and $(0) \mathrm{E} 14$. The lines are drawn by inspection only.

helix macrodipole, are much less helical than the corresponding peptides at low $\mathrm{pH}\left(\mathrm{Glu}^{0}\right)$. Likewise, the peptide $\mathrm{E} 2$, with the Glu situated near the positive pole of the helix macrodipole, shows higher helicity at $\mathrm{pH} 7.0$ than at $\mathrm{pH} 2.5$. The crossover point, that is, the point at which the $\mathrm{Glu}^{-}$and $\mathrm{Glu}^{0}$ forms of a peptide are equally helical, appears around position 5 or 6 . Since this crossover point is not in the middle of the sequence, it implies that the intrinsic helix-forming tendency of Glu changes with the ionization state of the side-chain carboxylate. The dashed line in Figure 1 is the best fit to the data using the charge-dipole modification of the Lifson-Roig theory and gives $w\left(E^{-}\right)=0.45$, a value less than that found for $\mathrm{Glu}^{0}$ $\left(w\left(\mathrm{E}^{0}\right)=0.66\right)$.

Glu-Lys Peptides. There are six peptides designed to study the effects of spacing and orientation of an isolated pair of Glu and Lys residues; their sequences are shown in Table I. In the four Glu-Lys peptides Glu is always N-terminal to Lys, whereas in the Lys-Glu peptides the order of the guest residues is reversed. Figure 2 shows the effect of $\mathrm{pH}$ on the helicity of the Glu-Lys peptides at $10 \mathrm{mM} \mathrm{NaCl}$. The order of helix stabilization under all conditions is $(i, i+4)>(i, i+3)$ $\gg(i, i+2) \approx(i, i+1)$.

The change in helicity with $\mathrm{pH}$ for the Glu-Lys peptides is not caused solely by the ionization of the Glu residue, as peptides $\mathrm{E} 5$ and $\mathrm{E} 6$ have helicities that are independent of $\mathrm{pH}$ over this range (see Table II and Figure 3). Therefore, the change in helicity with $\mathrm{pH}$ for the Glu-Lys peptides must be a consequence of altered side-chain interactions in $\mathrm{Glu}^{0}-\mathrm{Lys}{ }^{+}$ compared to $\mathrm{Glu}^{-}-\mathrm{Lys}^{+}$. For the peptides with $(i, i+4)$ and $(i, i+3)$ spacing, the amount of helix is higher at $\mathrm{pH} 7.0$ than at $\mathrm{pH} 2.5$, suggesting an increased stabilization of the helix by the charged ion-pair, whereas the opposite trend is observed for the $(i, i+2)$ and $(i, i+1)$ peptides.
In considering the effects of $\mathrm{pH}$ on the Lys-Glu peptides, it is clear that two factors must be operating. Ionization of an isolated Glu residue in positions 9 and 10 does have an effect on the observed helicity (see Figure 1 and Table II) and will contribute to the change in helicity with $\mathrm{pH}$; the second effect is the difference between the side-chain interactions of $\mathrm{Glu}^{0}-\mathrm{Lys}^{+}$and $\mathrm{Glu}^{-}-\mathrm{Lys}^{+}$. Therefore, in order to characterize the energetics of a specific $\mathrm{Glu}^{-}-\mathrm{Lys}^{+}$side-chain interaction, the effects of a difference between the intrinsic helix-forming tendencies of $\mathrm{Glu}^{\circ}$ and $\mathrm{Glu}^{-}$and the contributions of $\mathrm{Glu}^{-}$and $\mathrm{Lys}^{+}$to the charge-dipole interaction must be evaluated separately.

Side-Chain Interactions. The energetics of specific sidechain interactions in the Glu-Lys and Lys-Glu peptides can be analyzed with our modifications of the Lifson-Roig theory (see Experimental Procedures and the Appendix). The results of the side-chain interaction analysis are provided in Tables III-V at three different $\mathrm{NaCl}$ concentrations. At low $\mathrm{pH}$, the observed helicities for peptides with $(i, i+1)$ and $(i, i+2)$ spacing (E5K6 and E5K7) can be accounted for, within error, without introducing any interaction free energy between the side chains. On the other hand, the peptides with $(i, i+3)$ and $(i, i+4)$ spacing require a substantial additional free energy of interaction $\left(\approx 300 \mathrm{cal} \mathrm{mol}^{-1}\right)$ between the side chains in order to account for the observed helicities. All the interaction energies at low $\mathrm{pH}$ are independent of the concentration of $\mathrm{NaCl}$.

The results at $\mathrm{pH} 7.0$, where both Glu and Lys residues are ionized, are quite different from those found at low $\mathrm{pH}$. For all four peptides with either $(i, i+3)$ or $(i, i+4)$ spacing, there is a large side-chain interaction present at low ionic strength. The side-chain interaction decreases with increasing $\mathrm{NaCl}$ concentration, as expected for an electrostatic interaction. The two peptides with either $(i, i+1)$ or $(i, i+2)$ spacing, on the other hand, have side-chain interactions that destabilize the helical conformation (or stabilize the coil conformation) at low ionic strength. This helix destabilization is screened by $\mathrm{NaCl}$, and the side-chain interaction energy approaches 0 at higher ionic strengths.

Figure 4 shows the effect of $\mathrm{NaCl}$ on the Gibbs energy of the side-chain interaction for the Glu-Lys and Lys-Glu peptides at low and neutral $\mathrm{pH}$. At low $\mathrm{pH}$, the interaction energies are not dependent on the ionic strength of the solution and only the peptides with $(i, i+3)$ or $(i, i+4)$ spacing show measurable side-chain interactions. The calculated interaction energy $\left(\approx 300 \mathrm{cal} \mathrm{mol}^{-1}\right)$ does not depend on the orientation of the $\mathrm{Glu}^{0}$ and Lys ${ }^{+}$residues, as long as the spacing is either $(i, i+3)$ or $(i, i+4)$. When the Glu is ionized, two interesting results are obtained. For the peptides with $(i, i+3)$ or $(i, i+4)$ spacing, the side-chain interaction energy increases by $\approx 100$ $150 \mathrm{cal} \mathrm{mol}^{-1}$ at low ionic strength. This increase in the sidechain interaction energy can be screened by $\mathrm{NaCl}$; at $2.5 \mathrm{M}$ $\mathrm{NaCl}$ the interaction energy is identical for the $\mathrm{Glu}^{-}-\mathrm{Lys}^{+}$ and the $\mathrm{Glu}^{0}-\mathrm{Lys}^{+}$combinations. For the peptides with $(i$, $i+2)$ or $(i, i+1)$ spacing, the fully ionized pair of residues is destabilizing to the helical conformation at low ionic strength. This destabilization can also be screened by $\mathrm{NaCl}$, resulting in no net stabilization at high ionic strengths.

There are two single Glu peptides, E7 and E12, which show larger helicities than those expected from the intrinsic helixforming tendencies of $\mathrm{Glu}^{-}$and $\mathrm{Glu}^{\circ}$ (Table II and Figure 1). Each peptide has an $(i, i+4)$ QE residue pair that provides the possibility of a stabilizing side-chain interaction. The energetics of these interactions can be assessed in the same manner as that described for the Glu-Lys peptides. Table VI 
Table III: Side-Chain Interactions in $10 \mathrm{mM} \mathrm{NaCl}^{a}$

\begin{tabular}{lcccccc}
\hline peptide & $w_{\text {app }}\left(\mathrm{K}_{j}^{+}\right)$ & $w_{\text {app }}\left(\mathrm{E}_{i}^{-}\right)$ & $f_{\mathrm{H}}(\mathrm{pH} 2.5)$ & $\Delta G^{\circ}\left(\mathrm{E}^{0} \mathrm{~K}^{+}\right), \mathrm{cal} \mathrm{mol}^{-1}$ & $f_{\mathrm{H}}(\mathrm{pH} 7.0)$ & $\Delta G^{\circ}\left(\mathrm{E}^{-} \mathrm{K}^{+}\right) \mathrm{cal} \mathrm{mol}^{-1}$ \\
\hline E5K6 & 0.53 & 0.65 & 0.26 & 0 & 0.22 & 200 \\
E5K7 & 0.60 & 0.65 & 0.28 & -95 & 0.23 & 180 \\
E6K9 & 0.68 & 0.63 & 0.33 & -285 & 0.35 & -380 \\
E6K10 & 0.75 & 0.63 & 0.37 & -340 & 0.39 & -470 \\
K6E9 & 0.53 & 0.41 & 0.31 & -290 & 0.28 & -380 \\
K6E10 & 0.53 & 0.39 & 0.30 & -320 & 0.32 & -460 \\
\hline
\end{tabular}

${ }^{a}$ Calculated with $\left\langle w_{\text {host }}\right\rangle=1.43$ and $v^{2}=0.0038$ for both $\mathrm{pH} 2.5$ and 7.0. For the low-pH calculations, $w\left(\mathrm{E}^{0}\right)=0.66$. The $w_{\text {app }}\left(\mathrm{E}_{10}^{-}\right)$value was calculated from the expected helicity shown in Figure 1. The errors on the $\Delta G^{\circ}$ values range from \pm 20 to $\pm 50 \mathrm{cal} \mathrm{mol}^{-1}$; negative values of $\Delta G^{\circ}$ represent helix-stabilizing interactions.

\begin{tabular}{ccccccc}
\hline Table IV: & Side-Chain Interactions in $1.0 \mathrm{M} \mathrm{NaCl}^{a}$ \\
\hline peptide & $w_{\mathrm{app}}\left(\mathrm{K}_{j}^{+}\right)$ & $w_{\mathrm{app}}\left(\mathrm{E}_{i}^{-}\right)$ & $f_{\mathrm{H}}(\mathrm{pH} 2.5)$ & $\Delta G^{\circ}\left(\mathrm{E}^{0} \mathrm{~K}^{+}\right), \mathrm{cal} \mathrm{mol}^{-1}$ & $f_{\mathrm{H}}(\mathrm{pH} 7.0)$ & $\Delta G^{\circ}\left(\mathrm{E}^{-} \mathrm{K}^{+}\right), \mathrm{cal} \mathrm{mol}^{-1}$ \\
\hline E5K6 & 0.61 & 0.52 & 0.31 & -40 & 0.28 & 0 \\
E5K7 & 0.67 & 0.52 & 0.33 & -120 & 0.29 & 60 \\
E6K9 & 0.75 & 0.56 & 0.38 & -270 & 0.36 & -320 \\
E6K10 & 0.82 & 0.56 & 0.43 & -360 & 0.40 & -390 \\
K6E9 & 0.61 & 0.49 & 0.37 & -280 & 0.32 & -330 \\
K6E10 & 0.61 & 0.47 & 0.34 & -350 & 0.33 & -410 \\
\hline
\end{tabular}

${ }^{a}$ Calculated with $\left(w_{\text {host }}\right.$ ) $=1.46$ and $v^{2}=0.0038$ for both $\mathrm{pH} 2.5$ and 7.0. For the low-pH calculations, $w\left(\mathrm{E}^{0}\right)=0.70$. The $w\left(\mathrm{E}_{10}^{-}\right)$value was calculated from the expected helicity of E10 from the data in Table $I$. The errors on the $\Delta G^{\circ}$ values range from \pm 20 to $\pm 50 \mathrm{cal} \mathrm{mol}^{-1}$; negative values of $\Delta G^{\circ}$ represent helix-stabilizing interactions.

\begin{tabular}{lcccccc}
\hline Table V: & \multicolumn{7}{l}{ Side-Chain Interactions in $2.5 \mathrm{M} \mathrm{NaCl}{ }^{a}$} \\
\hline peptide & $w_{\text {app }}\left(\mathrm{K}_{j}^{+}\right)$ & $w_{\text {app }}\left(\mathrm{E}_{i}^{-}\right)$ & $f_{\mathrm{H}}(\mathrm{pH} 2.5)$ & $\Delta G^{\circ}\left(\mathrm{E}^{0} \mathrm{~K}^{+}\right), \mathrm{cal} \mathrm{mol}^{-1}$ & $f_{\mathrm{H}}(\mathrm{pH} 7.0)$ & $\Delta G^{\circ}\left(\mathrm{E}^{-} \mathrm{K}^{+}\right), \mathrm{cal} \mathrm{mol}^{-1}$ \\
\hline E5K6 & 0.69 & 0.50 & 0.31 & -80 & 0.27 & -40 \\
E5K7 & 0.76 & 0.50 & 0.32 & -100 & 0.29 & -110 \\
E6K9 & 0.84 & 0.55 & 0.39 & -310 & 0.34 & -290 \\
E6K10 & 0.91 & 0.55 & 0.41 & -330 & 0.37 & -350 \\
K6E9 & 0.69 & 0.42 & 0.36 & -270 & 0.27 & -270 \\
K6E10 & 0.69 & 0.40 & 0.35 & -300 & 0.27 & -330 \\
\hline
\end{tabular}

${ }^{a}$ Calculated with $\left\langle w_{\text {host }}\right\rangle=1.43$ and $v^{2}=0.0038$ for both $\mathrm{pH} 2.5$ and 7.0 . For the low-pH calculations, $w\left(\mathrm{E}^{0}\right)=0.72$. The $w_{\text {app }}\left(\mathrm{E}_{10}^{-}\right)$value was calculated from the expected helicity of $E 10$ from the data in Table $I$. The errors on the $\Delta G^{\circ}$ values range from \pm 20 to \pm 50 cal mol ${ }^{-1} ;$ negative values of $\Delta G^{\circ}$ represent helix-stabilizing interactions.

shows the results of this analysis and compares all side-chain interactions that have $(i, i+4)$ spacing of side chains.

\section{DISCUSSION}

Separation of Side-Chain Interactions from Other HelixStabilizing Effects. The role of side-chain electrostatic interactions in stabilizing an $\alpha$-helix has been appreciated for some time (Fairman et al., 1990; Gans et al., 1991; Marqusee \& Baldwin, 1987; Scholtz \& Baldwin, 1992). The C-peptide from ribonuclease $A$ contains several interactions between side chains that provide measurable stability to the $\alpha$-helical conformation of the peptide in aqueous solution. Despite the accepted role of specific side-chain interactions, a direct measurement of their contribution to the overall stability of an isolated helical peptide has been difficult. The first $\alpha$-helical peptides of de novo design contained several pairs of Glu and Lys residues in an alanine peptide (Marqusee \& Baldwin, 1987). The basic design employed by Marqusee and Baldwin was used by other groups to look at the effects of spacing and orientation of different pairs of charged residues (HuyghuesDespointes et al., 1993b; Marqusee \& Baldwin, 1990; Merutka et al., 1990; Merutka \& Stellwagen, 1991; Stellwagen et al., 1992). Although these studies demonstrated the importance of side-chain interactions and also differences between the interactions of pairs of charged residues with different orientations and spacings, a detailed quantitation of the energetics was not possible because there are multiple interactions present in each peptide. This problem has been circumvented by using an isolated pair of charged residues in an otherwise neutral host peptide.

There are two main electrostatic interactions observed when charged residues are placed in a helical peptide: the interaction between the charged side chains and an interaction between each charged side chain and the helix macrodipole. In order to understand the former, a complete accounting of the chargedipole interaction must be obtained. The interaction of an isolated charged residue with the helix dipole has been investigated recently for $\mathrm{His}^{+}$(Armstrong \& Baldwin, 1993) and Asp- (Huyghues-Despointes et al., 1993a). The Glu series of peptides (Figure 1) shows a behavior similar to that found in these other reports.

The standard treatments of the helix-coil transition do not take specific side-chain interactions into account, but merely use intrinsic helix-forming tendencies ( $w$ - or $s$-values) and nucleation parameters $\left(v^{2}\right.$ or $\left.\sigma\right)$ to calculate the expected helicity of a given peptide. The standard Lifson-Roig treatment has been modified here in order to determine the electrostatic interactions between a charged side chain and the helix macrodipole. This simple modification of the model is able to describe the behavior of a charged residue in a neutral host peptide (Figure 1) and provides a method for the determination of the intrinsic helix-forming tendency of a charged residue. For $\mathrm{Glu}^{-}$, the observed $w\left(\mathrm{E}^{-}\right)$is 0.45 , whereas the neutral form of Glu gives $w\left(\mathrm{E}^{0}\right)=0.66$; the charged form of the amino acid is less helix stabilizing than the neutral form. This same result is obtained for His (Armstrong \& Baldwin, 1993), but not for Asp (Huyghues-Despointes et al., 

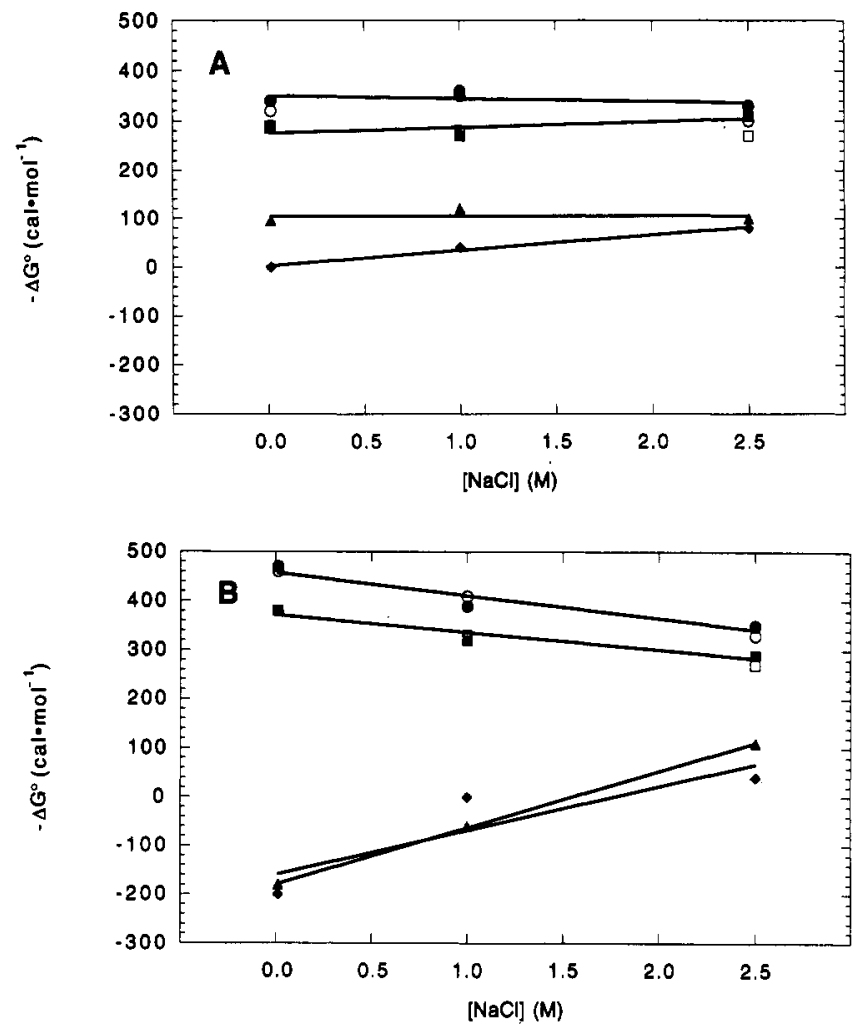

Figure 4: Effect of $[\mathrm{NaCl}]$ on the energetics of the side-chain interactions in the Glu-Lys and Lys-Glu series of peptides. Panel A shows data collected at $\mathrm{pH} 2.5\left(\mathrm{Glu}^{0}-\mathrm{Lys}^{+}\right)$; panel $\mathrm{B}$, at $\mathrm{pH} 7.0$ $\left(\mathrm{Glu}^{-}-\mathrm{Lys}^{+}\right)$. The peptides are ( $\bullet$ E5K6, (A) E5K 7, () E6K9, (•) E6K10, (ם) K6E9, and

Table VI: Comparison of $(i, i+4)$ Interactions in $10 \mathrm{mM} \mathrm{NaCl}$ at 0 ${ }^{\circ} \mathrm{C}$

\begin{tabular}{|c|c|c|}
\hline peptide & interaction & $\left.\Delta G^{\circ}(\mathrm{cal} \mathrm{mol})^{-1}\right)$ \\
\hline E6K10 & $\mathrm{Glu}^{0}{ }^{0 . . . \mathrm{Lys}^{+}}$ & -340 \\
\hline E6K10 & $\mathrm{Glu}^{-} \cdots \mathrm{Lys}^{+}$ & -470 \\
\hline K6E10 & Lys $^{+} \ldots \mathrm{Glu}^{0}$ & -320 \\
\hline K6E10 & Lys $^{+}{ }^{\ldots . . . G l u} u^{-}$ & -460 \\
\hline Q3E7 & $\mathrm{Gln} \cdots \mathrm{Glu} u^{0}$ & -380 \\
\hline Q3E7 & Gln $\cdots \mathrm{Glu}^{-}$ & -340 \\
\hline Q8E12 & Gln...Glu ${ }^{0}$ & -300 \\
\hline Q8E12 & Gln...Glu- & -270 \\
\hline
\end{tabular}

1993a) where the charged and uncharged forms have identical $w$-values. The difference in helix propensities for the charged and uncharged forms of Glu has been noted previously (Stellwagen et al., 1992); we find a similar result here. The intrinsic helix-forming tendencies determined here $(s=0.62$ for $\mathrm{Glu}^{0}$ and 0.42 for $\mathrm{Glu}^{-}$) are substantially different from the values found in the host-guest studies of Maxfield et al. (1975), who found s-values of 1.47 and 0.96 for $\mathrm{Glu}^{0}$ and $\mathrm{Glu}^{-}$, respectively.

Properties of Ion-Pair and Hydrogen-Bond Interactions. After the effects of charge-dipole interactions are removed, it is possible to determine the free energy of the interaction between side chains of the charged residues. An isolated pair of Glu-Lys residues has been placed in a neutral host peptide, and the different interaction energies between the side chains have been determined for four different spacings and orientations of the charged residues. The principal finding is that there are significant stabilizing interactions between the side chains when the spacing between the residues is close to the helical repeat of 3.6 residues per turn. The nature of this interaction is interesting. A strong, singly charged hydrogen bond between Glu and Lys is found when the spacing is either $(i, i+3)$ or $(i, i+4)$, regardless of the orientation of the Glu and Lys residues. The strength of this singly-charged hydrogen bond does not depend upon the ionic strength of the solution up to $2.5 \mathrm{M} \mathrm{NaCl}$. Upon ionization of the Glu residue, an additional ion-pair interaction is present that can be screened by added $\mathrm{NaCl}$.

The ion-pair interaction between $\mathrm{Glu}^{-}$and $\mathrm{Lys}^{+}$when the spacing is $(i, i+1)$ or $(i, i+2)$ is helix destabilizing. This coilstabilizing interaction is lost by the addition of $\mathrm{NaCl}$ or by neutralization of the $\mathrm{Glu}^{-}$residue by lowering the $\mathrm{pH}$ of the solution. Although the maximum destabilization observed for the $(i, i+1)$ or $(i, i+2)$ peptides is only $\approx 200 \mathrm{cal} \mathrm{mol}^{-1}$, or about half of the maximum stabilization observed in the $(i, i+4)$ and $(i, i+3)$ peptides, it is significant and illustrates the importance of considering both helix-stabilizing and helixdestabilizing interactions in a given peptide. The original Glu-Lys peptides described by Marqusee and Baldwin (1987) have $(i, i+4)$ and $(i, i+3)$ arrangements of Glu and Lys; however, the $(i, i+4)$ peptide also contains $(i, i+1)$ spacings and the $(i, i+3)$ peptide has $(i, i+2)$ spacings. This design complicates the interpretation of the strength of the ion pairs in these original peptides [see Perutz and Fermi (1988)]. Likewise, the peptides used by Gans et al. (1991) in their determination of the strength of ion pairs in a helical peptide contain multiple Glu and Lys residues with a variety of spacings. The peptides employed in our study provide a simple system for determining the energetics of specific side-chain interactions and for taking complete account of the chargedipole interaction.

Comparison of Ion-Pair and Hydrogen-Bond Interactions. There are three main side-chain interactions that are observed in these peptides: an ion-pair interaction, a singly charged hydrogen bond, and a neutral hydrogen bond. The $(i, i+3)$ and $(i, i+4) \mathrm{Glu}-\mathrm{Lys}$ peptides show strong ion-pair interactions at neutral $\mathrm{pH}$ and moderate singly-charged hydrogen bonds at low pH. A neutral hydrogen bond of moderate strength is observed between Gin and Glu in two of the Glu peptides at low $\mathrm{pH}$. The data in Table VI compare the strength of each interaction for $(i, i+4)$ side-chain pairs. The main result is that a hydrogen bond between side chains can contribute substantial stability to the $\alpha$-helical structure. The ionization of one side chain increases the strength of the hydrogen bond, while complete ionization of both side chains provides greater stabilization; however, the strength of the interaction of the complete ion pair depends on the ionic strength of the solution (see Figure 4).

The strength of ion-pair interactions in an isolated $\alpha$-helical peptide has been measured by Gans et al. (1991) using peptides with multiple Glu and Lys residues with various spacings. The calculated strength of a Glu-Lys ion-pair is $\approx 0.5 \mathrm{kcal}$ $\mathrm{mol}^{-1}$ according to their analysis. In proteins, the contributions of surface-exposed ion pairs to the stabilization of the folded state is in this same range $\left[0.0-0.5 \mathrm{kcal} \mathrm{mol}^{-1}\right.$; Dao-pin et al. (1991); Horovitz et al. (1990)], whereas buried ion pairs can make much larger contributions (Anderson et al., 1990). Our system is designed to separate cleanly the contributions of ion-pair interactions from all of the other aspects of structure formation in these peptides. We find a maximum $\mathrm{Glu}^{-}-\mathrm{Lys}^{+}$ ion-pair interaction of $\approx 0.45 \mathrm{kcal} \mathrm{mol}^{-1}$ (Tables III-V at low $\mathrm{NaCl}$ concentration when the spacing $[(i, i+3)$ or $(i, i+4)]$ is correct for an $\alpha$-helix. When the spacing is $(i, i+1)$ or $(i$, $i+2$ ), the ion pair is helix destabilizing by $\approx 0.2 \mathrm{kcal} \mathrm{mol}^{-1}$. This behavior illustrates the importance of considering all possible spacings and orientations of the charged side chains in the helical peptide. 
At low $\mathrm{pH}$, where Glu is neutralized, there are significant side-chain interactions present in the Glu-Lys peptides with $(i, i+3)$ and $(i, i+4)$ spacings. Likewise, in two of the Glu peptides (E7 and E12) at all values of $\mathrm{pH}$, there are stabilizing Gln-Glu interactions for the $(i, i+4)$ spacing. This $\mathrm{Gln}-\mathrm{Glu}$ interaction is quite specific compared to the Glu-Lys interactions: only the $(i, i+4) \mathrm{Gln}-\mathrm{Glu}$ arrangement is helix stabilizing. Other orientations and spacings show no interaction (Figure 1 and Table II). An $(i, i+4)$ hydrogen-bond interaction with similar properties is also found for the GlnAsp pair (Huyghues-Despointes et al., 1993a). Further work is needed to determine the reason for the specific orientation and spacing of the Gln-Glu and Gln-Asp side-chain interactions. All of the observed hydrogen-bond interactions, either between a charged and a neutral side chain or between two neutral side chains, have similar strengths. These hydrogen bonds are not affected by the ionic strength of the solution (Tables III-V and Figure 4A) and are substantial in magnitude $\left(\approx 0.3 \mathrm{kcal} \mathrm{mol}^{-1}\right)$.

The role of specific hydrogen-bond interactions in stabilizing an isolated $\alpha$-helical peptide has not been measured directly prior to this report. The approach used here enables us to identify and quantify the energetics of these specific hydrogenbond interactions. The stabilization free energy found for hydrogen bonds in these $\alpha$-helical peptides is within the range observed in many biological systems (Shirley et al., 1992), despite the complexities inherent in most estimations of hydrogen bond energies (Morgan et al., 1991). These peptides, and the model employed in the analysis, present a simple system for evaluating the energetics of defined, isolated interactions. Our results suggest that the role of specific hydrogen bonds in peptide and protein stability may be substantial.

\section{ACKNOWLEDGMENT}

We thank John Schellman for many helpful discussions and financial support for H. Q., members of the Baldwin laboratory for numerous discussions and review of the manuscript, and the Mass Spectrometry Facility, University of California at San Francisco (supported by NIH Grant RR 01614), for verification of peptide identity.

\section{APPENDIX}

Recent experiments on the effects of substitution of a charged residue in a helical peptide have shown that both the amount of helical structure and the $\mathrm{p} K_{\mathrm{a}}$ of the charged residue vary with the position of the residue in the helical peptide (Armstrong \& Baldwin, 1993; Huyghues-Despointes et al., 1993a). Specific side-chain interactions can also affect the amount of helix observed in a helical peptide (Fairman et al., 1990; Scholtz \& Baldwin, 1992). The standard treatments of the helix-coil transition (Lifson \& Roig, 1961; Zimm \& Bragg, 1959) are unable to take specific side-chain interactions into account; therefore several modifications of the basic theories have been developed. Since only short peptides will be considered, the one-sequence approximation of the theory will be used (Qian \& Schellman, 1992).

Charge-Dipole Interactions. The basic framework of the model used here was described by Lifson and Roig (1961), and we add the assumption that there is only one helical segment per chain. The helix macrodipole is modeled by the simple Coulombic interaction of two point charges placed at either end of the helical stretch of residues in each conformation contained in the partition function. Although there are alternative ways to model the helix dipole, we elected to use this simple representation in our initial approach. A point charge of $+0.5 q$ is placed $1 \AA$ away from the $\mathrm{N}$-terminus $\left(d_{\mathrm{N}}\right.$ $=1$ ), and a charge of $-0.5 q$ is placed $1 \AA$ away from the C-terminus $\left(d_{C}=1\right)$ of each helical segment (Sheridan et al., 1982). For each partial helical conformation that contributes to the partition function, an electrostatic term is included to account for the interaction of a charged side chain with the point charges which model the helix macrodipole. The distance between the charged side chain and the helix axis is $r_{\mathrm{n}}$ and is set to $5 \AA$ (Vásquez \& Scheraga, 1988), and the rise along the helical axis, $r_{\mathrm{p}}$, is $1.5 \AA$ per helical residue. The new partition function can be written as:

$$
Q_{1}=q+\sum_{m=1}^{N-2} v^{2} w^{m} \sum_{j=1}^{N-m-1} \exp [-E(j, m, k) / R T]
$$

where $E(j, m, k)$ is the charge-dipole interaction between charged residue $k$ and the dipole when the helical segment is between residues $j$ and $(j+m+1)$ :

$$
\begin{array}{r}
E(j, k, m)=\frac{q_{\mathrm{dp}} q}{D}\left(\frac{1}{\left(\left[(j+m+1-k) r_{\mathrm{p}}+d_{\mathrm{C}}\right]^{2}+r_{\mathrm{n}}^{2}\right)^{1 / 2}}-\right. \\
\left.\frac{1}{\left(\left[(j-k) r_{\mathrm{p}}-d_{\mathrm{N}}\right]^{2}+r_{\mathrm{n}}^{2}\right)^{1 / 2}}\right)
\end{array}
$$

with $q$ and $q_{\mathrm{dp}}$ as the charges on the side chain and the helix macrodipole, respectively, $D$ as the dielectric constant of the medium, and $d_{\mathrm{N}}$ and $d_{\mathrm{C}}$ as the additional distances beyond the ends of the helical stretch for the placement of $q_{\mathrm{dp}}$.

The helix macrodipole can also perturb the $\mathrm{p} K_{\mathrm{a}}$ of a charged residue. This perturbation can be modeled as well. In eq 1 , it was assumed that residue $k$ is permanently charged; however, if the $\mathrm{pH}$ of the solution is near the $\mathrm{p} K_{\mathrm{a}}{ }^{0}$ of the charged residue (the $\mathrm{p} K_{\mathrm{a}}$ value in the absence of any electrostatic perturbation), an equilibrium between the charged and neutral forms exists. The partition function in eq 1 can be further modified to give

$$
\begin{gathered}
Q=1+K_{\mathrm{a}}^{0}\left[\mathrm{H}^{+}\right]+\sum_{j=1}^{N-2}\left\{1+K_{\mathrm{a}}^{0}\left[\mathrm{H}^{+}\right] \exp [-E(j, m, k) / R T]\right\} \\
Q=Q_{0}+K_{\mathrm{a}}^{0} Q_{1}\left[\mathrm{H}^{+}\right]
\end{gathered}
$$

where $\mathrm{Q}_{0}$ is the original partition function defined by Lifson and Roig [see Qian and Schellman (1992)] and $Q_{1}$ is defined in eq 1. The apparent association constant for the charged residue is

$$
K_{\mathrm{a}}^{\mathrm{app}}=K_{\mathrm{a}}^{0} Q_{1} / Q_{0}
$$

which gives the apparent $\mathrm{p} K_{\mathrm{a}}$ for the charged group:

$$
\mathrm{p} K_{\mathrm{a}}^{\mathrm{app}}=-\log K_{\mathrm{a}}^{\mathrm{app}}=\mathrm{p} K_{\mathrm{a}}^{0}-\log Q_{1}+\log Q_{0}
$$

The free energy difference between the charged and neutral peptides, $\Delta \Delta G^{\circ}$, is

$$
\Delta \Delta G^{0}=-R T \ln \left(Q_{1} / Q_{0}\right)=-2.3 R T \Delta\left(\mathrm{p} K_{\mathrm{a}}\right)
$$

These modifications have been incorporated in to the onesequence approximation of the Lifson-Roig theory. The only three parameters needed for a complete description of the position dependence of a charged residue in a host peptide are: $\left\langle w_{\text {host }}\right\rangle, v^{2}$, and $w$ (guest). Dielectric constants (eq 2) between 50 and $80 \mathrm{D}$ appear to fit all of the available data [Figure 1 and Armstrong and Baldwin (1993); HuyghuesDespointes et al., 1993a], so $D=60$ has been used.

Interactions between Side Chains. In order to incorporate interactions between specific side chains, a modification of the original Lifson-Roig treatment has been developed. Using 
the nesting block method described by Robert (1990), the partition function in the absence of any side chain interactions can be written as:

$$
\begin{aligned}
& Q=\left\langle\mathbf{L}\left|\mathrm{W}_{1} \ldots \mathrm{W}_{i-1} \mathrm{~W}_{i} \ldots \mathrm{W}_{j} \mathrm{~W}_{j+1} \ldots \mathrm{W}_{N}\right| \mathbf{R}\right\rangle \\
& =\sum_{\mathbf{m}} \sum_{\mathbf{n}}\left\langle\mathbf{L}\left|\mathbf{W}_{1} \ldots \mathbf{W}_{i-1}\right| \mathbf{m}\right\rangle\left\langle\mathbf{m}\left|\mathbf{W}_{i} \ldots \mathbf{W}_{j}\right| \mathbf{n}\right\rangle\left\langle\mathbf{n}\left|\mathbf{W}_{j+1} \ldots \mathbf{W}_{N}\right| \mathbf{R}\right\rangle \\
& =\left(\left\langle\mathbf{L}\left|\mathbf{W}_{1} \ldots \mathrm{W}_{i-1}\right| 1\right\rangle,\left\langle\mathbf{L}\left|\mathbf{W}_{1} \ldots \mathrm{W}_{i-1}\right| 2\right\rangle,\left\langle\mathbf{L}\left|\mathrm{W}_{1} \ldots \mathrm{W}_{i-1}\right| 3\right\rangle, \ldots\right) \\
& \left(\begin{array}{cccc}
\left\langle 1\left|\mathrm{~W}_{i} \ldots \mathrm{W}_{j}\right| 1\right\rangle & \left\langle 1\left|\mathrm{~W}_{i} \ldots \mathrm{W}_{j}\right| 2\right\rangle & \left\langle 1\left|\mathrm{~W}_{i} \ldots \mathrm{W}_{j}\right| 3\right\rangle & \ldots \\
\left\langle 2\left|\mathrm{~W}_{i} \ldots \mathrm{W}_{j}\right| 1\right\rangle & \left\langle 2\left|\mathrm{~W}_{i} \ldots \mathrm{W}_{j}\right| 2\right\rangle & \left\langle 2\left|\mathrm{~W}_{i} \ldots \mathrm{W}_{j}\right| 3\right\rangle & \ldots \\
\left\langle 3\left|\mathrm{~W}_{i} \ldots \mathrm{W}_{j}\right| 1\right\rangle & \left\langle 3\left|\mathrm{~W}_{i} \ldots \mathrm{W}_{j}\right| 2\right\rangle & \left\langle 3\left|\mathrm{~W}_{i} \ldots \mathrm{W}_{j}\right| 3\right\rangle & \ldots \\
\ldots & \ldots & \ldots & \ldots
\end{array}\right) \times \\
& \left(\begin{array}{c}
\left\langle 1\left|\mathbf{W}_{j+1} \ldots \mathbf{W}_{N}\right| \mathbf{R}\right\rangle \\
\left\langle 2\left|\mathbf{W}_{j+1} \ldots \mathbf{W}_{N}\right| \mathbf{R}\right\rangle \\
\left\langle 3\left|\mathbf{W}_{j+1} \ldots \mathbf{W}_{N}\right| \mathbf{R}\right\rangle \\
\ldots
\end{array}\right)(7)
\end{aligned}
$$

where $\mathbf{W}_{k}$ is the correlation matrix for the residue in position $k,\langle\mathbf{L}|$ and $|\mathbf{R}\rangle$ are the left- and right-end vectors, and $\langle\mathbf{m}|$ and |n) are unit vectors:

$$
\begin{gathered}
\langle\mathbf{L}|=(0,0, \ldots, 1) \quad| \mathbf{R}\rangle=\left(\begin{array}{c}
1 \\
1 \\
\vdots \\
1
\end{array}\right) \\
\langle 1|=(1,0, \ldots, 0),\langle 2|=(0,1, \ldots, 0), \ldots \\
|1\rangle=\left(\begin{array}{c}
1 \\
0 \\
\vdots \\
0
\end{array}\right),|2\rangle=\left(\begin{array}{c}
0 \\
1 \\
\vdots \\
0
\end{array}\right), \ldots
\end{gathered}
$$

The entries in the matrix in eq $7,\left\langle\mathbf{m}\left|\mathbf{W}_{i} \ldots \mathbf{W}_{j}\right| \mathbf{n}\right\rangle$, are the partition function for the block between residues $i$ and $j$ when residue $i$ is in the $m$ state and $j$ is in the $n$ state. If we know the apparent $w$ and $v^{2}$ values for each of the residues, every term in eq 7 can be evaluated.

If there is an interaction between residues $i$ and $j$ when both residues are in the stabilized helical state $1(m=n=1)$, then an additional statistical weight, $p$, can be used to determine the strength of the side-chain interaction. The result is that instead of contributing $w$ to the partition function, one now contributes $p w$, but only when both of the residues involved in the side-chain interaction are in the stabilized helical conformation. Since we are using the one-sequence approximation of the Lifson-Roig theory, all the residues between $i$ and $j$ are required to be helical as well. The new partition function is:

$$
\begin{aligned}
& Q_{\mathrm{p}}=\left(\left\langle\mathbf{L}\left|\mathbf{W}_{1} \ldots \mathbf{W}_{i-1}\right| 1\right\rangle,\left\langle\mathbf{L}\left|\mathbf{W}_{1} \ldots \mathbf{W}_{i-1}\right| 2\right\rangle,\left\langle\mathbf{L}\left|\mathbf{W}_{1} \ldots \mathbf{W}_{i-1}\right| 3\right\rangle, \ldots\right) \\
& \left(\begin{array}{ccccc}
p & \left\langle 1 \mathrm{~W}_{i} \ldots \mathrm{W}_{j} \mid 1\right\rangle & \left\langle 1\left|\mathrm{~W}_{i} \ldots \mathrm{W}_{j}\right| 2\right\rangle & \left\langle 1\left|\mathrm{~W}_{i} \ldots \mathrm{W}_{j}\right| 3\right\rangle & \ldots \\
\left\langle 2\left|\mathrm{~W}_{i} \ldots \mathrm{W}_{j}\right| 1\right\rangle & \left\langle 2\left|\mathrm{~W}_{i} \ldots \mathrm{W}_{j}\right| 2\right\rangle & \left\langle 2\left|\mathrm{~W}_{i} \ldots \mathrm{W}_{j}\right| 3\right\rangle & \ldots \\
\left\langle 3\left|\mathrm{~W}_{i} \ldots \mathrm{W}_{j}\right| 1\right\rangle & \left\langle 3\left|\mathrm{~W}_{i} \ldots \mathrm{W}_{j}\right| 2\right\rangle & \left\langle 3\left|\mathrm{~W}_{i} \ldots \mathrm{W}_{j}\right| 3\right\rangle & \ldots \\
\ldots & \ldots & \ldots & \ldots
\end{array}\right) \\
& \left(\begin{array}{c}
\left\langle 1\left|\mathbf{W}_{j+1} \ldots \mathbf{W}_{N}\right| \mathbf{R}\right\rangle \\
\left\langle 2\left|\mathbf{W}_{j+1} \ldots \mathbf{W}_{N}\right| \mathbf{R}\right\rangle \\
\left\langle 3\left|\mathbf{W}_{j+1} \ldots \mathbf{W}_{N}\right| \mathbf{R}\right\rangle
\end{array}\right)
\end{aligned}
$$

A complete evaluation of eq 8 for the Glu-Lys peptides requires $\left\langle w_{\text {hast }}\right\rangle, v^{2}, w_{\text {app }}\left(\mathrm{E}_{i}^{-}\right)$, and $w_{\text {app }}\left(\mathrm{K}_{j}^{+}\right)$. The only remaining parameter is $p$, and the free energy of the sidechain interaction can be calculated from

$$
\Delta G^{\circ}=-R T \ln p
$$

Although we have illustrated this modification of the LifsonRoig theory using electrostatic side-chain interactions between Glu and Lys, the model is general and can describe the energetics of side-chain interactions regardless of the type of interaction involved. Computer programs based on both of these models have been written and are available from the authors.

\section{REFERENCES}

Anderson, D. E., Becktel, W. J., \& Dahlquist, F. W. (1990) $\mathrm{pH}$-induced denaturation of proteins: A single salt bridge contributes $3-5 \mathrm{kcal} / \mathrm{mol}$ to the free energy of folding of T4 lysozyme, Biochemistry 29, 2403-2408.

Åqvist, J., Luecke, H., Quiocho, F. A., \& Warshel, A. (1991) Dipoles localized at helix termini of proteins stabilize charges, Proc. Natl. Acad. Sci. U.S.A. 88, 2026-2030.

Armstrong, K. M., \& Baldwin, R. L. (1993) Charged histidine interacts with the $\alpha$-helix dipole at all positions in the helix, Proc. Natl. Acad. Sci. U.S.A. (submitted for publication).

Atherton, E., \& Sheppard, R. C. (1985) Solid phase peptide synthesis using $N$ - $\alpha$-fluorenyl-methoxycarbonylamino acid pentafluorophenyl esters, J. Chem. Soc., Chem. Commun. 3, 165-166.

Brandts, J. R., \& Kaplan, K. J. (1973) Derivative spectroscopy applied to tyrosyl chromophores. Studies on ribonuclease, lima bean inhibitor, insulin, and pancreatic trypsin inhibitor, Biochemistry 12, 2011-2024.

Chakrabartty, A., \& Baldwin, R. L. (1993) Comparison of amino acid helix propensities (" $s$ values") measured in different experimental systems, Protein Folding: In Vivo and In Vitro, pp 166-177, American Chemical Society, Washington, DC.

Chakrabartty, A., Schellman, J. A., \& Baldwin, R. L. (1991) Large differences in the helix propensities of alanine and glycine, Nature 351, 586-588.

Chakrabartty, A., Kortemme, T., Padmanabhan, S., \& Baldwin, R. L. (1993) Aromatic side-chain contribution to far-ultraviolet circular dichroism of helical peptides and its effect on measurement of helix propensities, Biochemistry 32, 55605565.

Dao-pin, S., Sauer, U., Nicholson, H., \& Matthews, B. W. (1991) Contributions of engineered surface salt bridges to the stability of T4 lysozyme determined by directed mutagenesis, Biochemistry 30, 7142-7153.

Fairman, R., Shoemaker, K. R., York, E. J., Stewart, J. M., \& Baldwin, R. L. (1990) The Glu 2-...Arg $10^{+}$side-chain interaction in the C-peptide helix of ribonuclease $\mathrm{A}$, Biophys. Chem. 37, 107-119.

Gans, P. J., Lyu, P. C., Manning, M. C., Woody, R. W., \& Kallenbach, N. R. (1991) The helix-coil transition in heterogeneous peptides with specific side-chain interactions: theory and comparison with CD spectral data, Biopolymers 31, 16051614.

Hol, W. G. J., van Duijnen, P. T., \& Berendsen, H. J. C. (1978) The $\alpha$-helix dipole and the properties of proteins, Nature 273, 443-446.

Horovitz, A., Serrano, L., Avron, B., Bycroft, M., \& Fersht, A. R. (1990) Strength and co-operativity of contributions of surface salt bridges to protein stability, J. Mol. Biol. 216, 10311044.

Huyghues-Despointes, B. M. P., Scholtz, J. M., \& Baldwin, R. L. (1993a) The effect of a single aspartate on helix stability at different positions in a neutral alanine-based peptide, Protein Sci. (in press).

Huyghues-Despointes, B. M. P., Scholtz, J. M., \& Baldwin, R. L. (1993b) Helical peptides with three pairs of Asp-Arg and 
Glu-Arg residues in different orientations and spacings, Protein Sci. 2, 80-85.

Lifson, S., \& Roig, A. (1961) On the theory of helix-coil transitions in biopolymers, J. Chem. Phys. 34, 1963-1974.

Lyu, P. C., Liff, M. I., Marky, L. A., \& Kallenbach, N. R. (1990) Side chain contributions to the stability of alpha-helical structure in peptides, Science 250, 669-673.

Marqusee, S., \& Baldwin, R. L. (1987) Helix stabilization by Glu-.... Lys $^{+}$salt bridges in short peptides of de novo design, Proc. Natl. Acad. Sci. U. S. A. 84, 8898-8902.

Marqusee, S., \& Baldwin, R. L. (1990) $\alpha$-Helix formation by short peptides in water, in Protein Folding, pp 85-94, American Association for the Advancement of Science, Washington, DC.

Maxfield, F. R., Alter, J. E., Taylor, G. T., \& Scheraga, H. A. (1975) Helix-coil stability constants for the naturally occurring amino acids in water. IX. Glutamic acid parameters from random poly(hydroxybutylglutamine-co-L-glutamic acid), $\mathrm{Mac}$ romolecules $8,479-491$.

Merutka, G., \& Stellwagen, E. (1991) Effect of amino acid ion pairs on peptide helicity, Biochemistry 30, 1591-1594.

Merutka, G., Lipton, W., Shalongo, W., Park, S., \& Stellwagen, E. (1990) Effect of central-residue replacement on the helical stability of a monomeric peptide, Biochemistry 29,7511-7515.

Morgan, B. P., Scholtz, J. M., Ballinger, M. D., Zipkin, I. D., \& Bartlett, P. A. (1991) Differential binding energy: a detailed evaluation of the influence of hydrogen-bonding and hydrophobic groups on the inhibition of thermolysin by phosphoruscontaining inhibitors, J. Am. Chem. Soc. 113, 297-307.

O'Neil, K. T., \& DeGrado, W. F. (1990) A thermodynamic scale for the helix-forming tendencies of the commonly occurring amino acids, Science 250, 646-651.

Padmanabhan, S., Marqusee, S., Ridgeway, T., Laue, T. M., \& Baldwin, R. L. (1990) Relative helix-forming tendencies of nonpolar amino acids, Nature 344, 268-270.

Perutz, M. F., \& Fermi, G. (1988) Stereochemistry of salt-bridge formation in $\alpha$-helices and $\beta$-strands, Proteins: Struct., Funct., Genet. 4, 294-295.

Qian, H., \& Schellman, J. A. (1992) Helix-coil theories: a comparative study for finite length polypepides, J. Phys. Chem. 96, 3987-3994.
Robert, C.H. (1990) A hierarchical "nesting" approach to describe the stability of alpha helicies with side-chain interactions, Biopolymers 30, 335-347.

Rohl, C. A., Scholtz, J. M., York, E. J., Stewart, J. M., \& Baldwin, R. L. (1992) Kinetics of amide proton exchange in helical peptides of varying chain lengths. Interpretation by the LifsonRoig equation, Biochemistry 31, 1263-1269.

Scholtz, J. M., \& Baldwin, R. L. (1992) The mechanism of alphahelix formation by peptides, Annu. Rev. Biophys. Biomol. Struct. 21, 95-118.

Scholtz, J. M., Marqusee, S., Baldwin, R. L., York, E. J., Stewart, J. M., Santoro, M., \& Bolen, D. W. (1991a) Calorimetric determination of the enthalpy change for the alpha-helix to coil transition of an alanine peptide in water, Proc. Natl. Acad. Sci. U.S.A. 88, 2854-2858.

Scholtz, J. M., Qian, H., York, E. J., Stewart, J. M., \& Baldwin, R. L. (1991b) Parameters of helix-coil transition theory for alanine-based peptides of varying chain lengths in water, Biopolymers 31, 1463-1470.

Scholtz, J. M., York, E. J., Stewart, J. M., \& Baldwin, R. L. (1991c) A neutral, water-soluble $\alpha$-helical peptide: the effect of ionic strength on the helix-coil equilibrium, J. Am. Chem. Soc. 113, 5102-5104.

Sheridan, R. P., Levy, R. M., \& Salemme, F. R. (1982) $\alpha$-Helix dipole model and electrostatic stabilization of $4-\alpha$-helical proteins, Proc. Natl. Acad. Sci. U.S.A. 79, 4545-4549.

Shirley, B. A., Stanssens, P., Hahn, U., \& Pace, C. N. (1992) Contribution of hydrogen bonding to the conformational stability of ribonuclease T1, Biochemistry 31, 725-732.

Stellwagen, E., Park, S. H., Shalongo, W., \& Jain, A. (1992) The contribution of residue ion pairs to the helical stability of a model peptide, Biopolymers 32, 1193-1200.

Vásquez, M., \& Scheraga, H. A. (1988) Effect of sequencespecific interactions on the stability of helical conformations in polypeptides, Biopolymers 27, 41-58.

Wada, A. (1976) The $\alpha$-helix as an electric macro-dipole, $A d v$. Biophys. 9, 1-63:

Zimm, B. H., \& Bragg, J. K. (1959) Theory of the phase transition between helix and random coil in polypeptide chains, J. Chem. Phys. 31, 526-535. 